UDC 621.3

DOI: $10.20535 /$ SRIT.2308-8893.2021.4.05

\title{
MODELING OF HEAT AND MASS TRANSFER PROCESSES IN THE MELTING ZONE OF POLYMERS
}

\author{
O. TROFYMCHUK, K. ZELENSKY, V. PAVLOV, K. BOVSUNOVSKA
}

\begin{abstract}
Issues related to the melting of the polymer mixture in cylindrical channels are considered. The peculiarity of the problem solved in this work is the presence in the channel of two-phase flows of a solid-liquid mixture under the influence of heating the outer surface of the cylinder and dissipative forces arising from friction of the mixture against the walls of this channel. The problems of heating the mixture, melting the polymer and determining the velocity of the phase transition boundary in the conditions of a mobile solid mixture due to the rotational motion of the mechanism that feeds the mixture into a cylindrical channel are considered. Mathematical models of certain processes are systems of differential equations with partial derivatives of mathematical physics; the corresponding boundary value problems are solved using numerical-analytical methods, which made it possible to obtain solutions in quadratures. The results of computer modeling of the developed algorithms are given.
\end{abstract}

Keywords: equivalent simplification, Stefan type problem, integral transformations, polymer mixture, Navier-Stokes equation, phase transition, Bessel functions.

\section{INTRODUCTION}

Single-screw extrusion is the most important method of processing polymeric materials, which explains the significant amount of available theoretical and experimental work in this area (for example [8-12]).

The process of processing the material in it is divided into four zones: the loading zone of the polymer mixture, in which the mixture is heated by an inductor to a certain temperature and dry friction against the wall of the extruder housing is heated to a temperature close to the melting point of the polymer; melting zones, where the polymer melt is formed (taking into account the phase transition solid mixture - liquid phase); the dosing zone in which the homogenization and crystallization of the melt; and areas of application of polymer insulation on the conductive core in the cable head. Given the significant cost of materials and equipment for polymer processing, an approach based on mathematical modeling of mass and heat transfer processes is preferred.

Mathematical modeling of mass and heat transfer processes in single-screw extruders provides an opportunity to determine the processing conditions of polymeric materials, determine the optimal operating conditions of existing extrusion lines for processing polymeric materials and create conditions for the development of such lines for a wide class of polymer products (insulating coating of cables for ultra-high voltages, production of wide range of polymer films).

In this case, taking into account the nonlinear properties of polymeric materials becomes essential during mathematical modeling of these processes, which affects the accuracy of determining the main parameters of both the 
polymer mixture in the loading zone and in the melting process when determining the melt temperature field of polymeric materials.

\section{PROBLEM STATEMENT}

The processes in the melting zone of the polymer mixture are crucital in terms of ensuring the quality of the original product.

The problem of modeling the processes of melting the polymer mixture is to solve the problem in the two-phase region of the solid phase - liquid phase, known as the Stefan type problem. The formulation of the problem of a phase transition in a two-phase region, formulated in [14, p. 50-53].

Many works are devoted to the description of problems such as Stefan and methods of their solution, for example [ $1-5]$. The vast majority consider one- and two-phase problems for one-dimensional models.

\section{Overview of mathematical models}

The solution of the corresponding boundary value problem, which describes the heating of the plug to the melting temperature, is similar to the solution of the corresponding boundary value problem in the loading zone. The difference is that in the two-phase heating zone-melting conditions at the phase boundary are functions of time (time movement of the boundary between the solid phase liquid phase).

In most works on modeling the processes of melting the polymer mixture, boundary value problems are formulated, which are described by systems of mass and heat transfer equations in a cylindrical coordinate system [1-8], which are considered "classical".

Taking into account the cylindrical geometry of the extruder, the equation of motion of the polymer melt and the temperature field of the melt can be described by the following system of equations:

continuity equation:

$$
\frac{\partial\left(\rho v_{z}\right)}{\partial z}+\frac{1}{r} \frac{\partial\left(r \rho v_{r}\right)}{\partial r}=0
$$

motion equation:

$$
\begin{gathered}
\frac{\partial v_{r}}{\partial t}+v_{r} \frac{\partial v_{r}}{\partial r}+v_{z} \frac{\partial v_{r}}{\partial z}=-\frac{1}{\rho} \frac{\partial p}{\partial r}+\mu_{e}\left[\Delta v_{r}+\frac{\partial^{2} v_{z}}{\partial r \partial z}\right]+g_{r} \\
\frac{\partial v_{z}}{\partial t}+v_{r} \frac{\partial v_{z}}{\partial r}+v_{z} \frac{\partial v_{z}}{\partial z}=-\frac{1}{\rho} \frac{\partial p}{\partial z}+\mu_{e}\left[\Delta v_{z}+\frac{1}{r} \frac{\partial^{2} v_{r}}{\partial r \partial z}+\frac{1}{r} \frac{\partial}{\partial z}\left(\frac{\partial v_{r}}{\partial r}\right)\right]+g_{z}
\end{gathered}
$$

energy equation:

$$
\begin{gathered}
\frac{\partial T}{\partial t}+v_{r} \frac{\partial T}{\partial r}+v_{z} \frac{\partial T}{\partial z}=k\left(\frac{\partial^{2} T}{\partial r^{2}}+\frac{1}{r} \frac{\partial T}{\partial r}+\frac{\partial^{2} T}{\partial z^{2}}\right)+\frac{A}{\rho c_{v}} q_{T} ; \\
q_{T}=-\left.T \frac{\partial p}{\partial T}\right|_{\rho}\left[\frac{1}{r} \frac{\partial\left(r v_{r}\right)}{\partial r}+\frac{\partial v_{z}}{\partial z}\right]+
\end{gathered}
$$




$$
+2 \mu_{e}\left[\left(\frac{\partial v_{r}}{\partial r}\right)^{2}+\left(\frac{\partial v_{z}}{\partial z}\right)^{2}+\left(\frac{\partial v_{z}}{\partial r}+\frac{\partial v_{r}}{\partial z}\right)^{2}+\left(\frac{\partial v_{\theta}}{\partial z}\right)^{2}\right]
$$

where $A-$ thermal equivalent of work; $c_{v}-$ specific heat of the liquid at a constant volume; $\mu_{e}$ - effective shear viscosity; $v$ - kinematic viscosity;

$$
\begin{gathered}
\mu_{e}=\mu_{0}\left(I_{2} / 2\right)^{\frac{n-1}{2} e^{-\beta\left(T-T_{0}\right)}}, \quad n=2 \rightarrow \mu_{e}=\mu_{0} \sqrt{I_{2} / 2} e^{-\beta\left(T-T_{0}\right)}, \\
(\nabla v)=\frac{1}{r} \frac{\partial\left(r v_{r}\right)}{\partial r}+\frac{\partial v_{z}}{\partial z},
\end{gathered}
$$

where $\mu_{0}$ - initial viscosity; $I_{2}$ - the second invariant of the strain rate tensor; $n$ - viscosity anomaly index; $v_{r}, v_{-} \theta, v_{z}$ - components of the velocity vector; $\tau_{i j}(i, j=r, \theta, z)$ - components of the stress tensor; $T$ - temperature; $\beta-$ temperature coefficient; $T_{0}$ - initial temperature (the temperature in left boundary of melting zone).

The expression $\left.(\partial p / \partial T)\right|_{\rho}$ is determined from the state equation. In the case of a constant value $\rho$ we have $p=\rho R T$ it is equal to $R \rho$.

The initial conditions for the equations (1) - (3) are obtained, taking into account the solution of the heat and mass transfer problem at the exit from the melting delay zone:

$$
v_{r}\left(r, z, t_{0}\right)=v z_{r}(r, z) \quad v_{z}\left(r, z, t_{0}\right)=v z_{z}(r, z) .
$$

The above system of equations does not take into account the dependence of the viscosity coefficient on the melt temperature, does not take into account the phase transition solid mixture - melt, which is a determining factor that affects the quality of the final product. There are no boundary conditions for heating the extruder body in the melting zone of the polymer and conditions on the left boundary of the polymer mixture - melt. These factors encourage the formulation of a nonlinear boundary value problem taking into account the above.

\section{PROBLEM SOLVING}

The problem of determining the velocity of the boundary between the solid phase and the liquid phase consists of the following steps.

\section{Heat transfer of solid mixture}

The boundary value problem of heating the solid mixture in the melting zone is similar to the problem of heating the "plug" in the loading zone. The difference is that the conditions change at the boundary of the $\Gamma$ phase transition solid phase - liquid phase in the sense that this boundary is mobile. The iterative procedure is similar to that described in the previous section, taking into account the need to calculate the integral transformations within the variable limits $r \in\left[r_{a}, r_{b}^{\prime}=r_{b}-\xi(z)\right] \subset \Omega_{t}$ : 


$$
\rho_{p} c_{v_{p}}\left(T_{p}\right)\left(V_{s n}^{r} \frac{\partial T_{p}}{\partial r}+V_{\mathrm{sn}}^{z} \frac{\partial T_{p}}{\partial z}+\frac{\partial T_{p}}{\partial t}\right)=\lambda_{p}\left(\frac{1}{r} \frac{\partial}{\partial r}\left(r \frac{\partial T_{p}}{\partial r}\right)+\frac{\partial^{2} T_{p}}{\partial z^{2}}\right)+q_{k}
$$

For polyethylene coefficient $c_{v_{p}}$ significantly depends on the heating temperature. On the base of experimental investigations this dependence approximated [3] as

$$
c_{v_{p}}=c_{0}+c_{1} T+c_{2} T^{2} \approx 2,5-0,024 T+5,7 \cdot 10^{-4} T^{2} .
$$

This expression corresponds to the original (in the space of integral transformations by spatial variables)

$$
D_{n k}^{(0)}(t)=\sum_{n=1, k=1}^{M} e^{-\alpha_{n k} t} \begin{cases}e 1_{n k} \sin \omega_{n k} t+e 2_{n k} \cos \omega_{n k} t, & \omega_{n k}<0 \\ e 1_{n k} \operatorname{sh} \omega_{n k} t+e 2_{n k} \operatorname{ch} \omega_{n k} t, & \omega_{n k}>0 .\end{cases}
$$

Then the solution in the first approximation will take the form

$$
T^{(1)}(r, z, t)=\sum_{n=1}^{M} \sum_{k=1}^{M} R\left(\delta_{n} r\right) Z\left(\beta_{k} z\right)\left[\frac{G_{n k}}{\eta_{n k}}\left(1-e^{-\eta_{n k} t}\right)+D_{n k}^{(0)}(t)\right] .
$$

Further approximations are implemented according to a similar scheme (Fig. 1):

$$
T^{(m)}(r, z, t)=\sum_{n=1}^{M} \sum_{k=1}^{M} R\left(\delta_{n} r\right) Z\left(\beta_{k} z\right)\left[\frac{G_{n k}}{\eta_{n k}}\left(1-e^{-\eta_{n k} t}\right)+D_{n k}^{(m-1)}(t)\right] .
$$
iteration.

In Fig. 1 shows the temperature distribution of sold polymer after 3-d

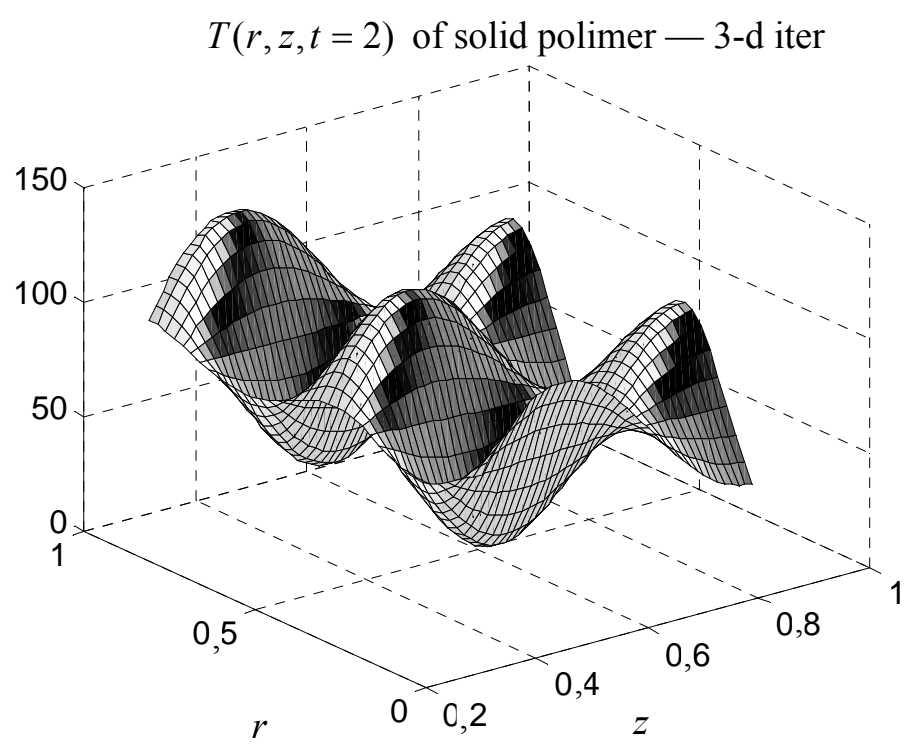

Fig. 1. Temperature of polimer at $t=2$

Therefore, the algorithm for solving the equation (4) differs from the one given in the previous section in the part of calculating integrals from Bessel functions of the second kind with respect to variable limits. Integral transformations of the nonlinear component of the thermal conductivity equation (4): 


$$
n r_{m, n, l}=\frac{1}{\left\|B_{m}\left(\beta_{m} r_{b}^{\prime}\right)\right\|} \int_{r_{a}}^{r_{b}-\xi(z)} B\left(\beta_{m} r\right) B\left(\beta_{n} r\right) B\left(\beta_{l} r\right) r d r .
$$

Naturally, the upper bound of the integrals of $r$ from similar to (4) expressions as the "plug" moves along the $z$ axis, it will decrease and move to the lower limit of $r_{a}$. The point $L$, at which $r_{b}^{\prime} \approx r_{a}$ will determine the length of the melting zone and the transition to the zone of homogenization and crystallization of the polymer melt.

\section{Solving the problem in the liquid phase}

Since the equation with respect to the velocity of the polymer solution contains pressure gradients in the solution, we begin solving the problem by solving the boundary value problem with respect to temperature. Taking into account the temperature dependence of the heat capacity coefficient $c_{v}$, as well as the presence of the convective component and the dissipative component $q_{T}$ we have

$$
\rho\left[c 0_{V}+L \delta\left(T-T^{*}\right)\right]\left(\frac{\partial T}{\partial t}+v_{r} \frac{\partial T}{\partial r}+v_{z} \frac{\partial T}{\partial z}\right)=\lambda^{+} \Delta T+q_{T} .
$$

Let us separate the linear part in this equation

$$
\frac{\partial T}{\partial t}=\frac{\lambda^{+}}{c 0_{V} \rho} \Delta T-C_{T}-\frac{1}{\rho}\left[L \delta\left(T-T^{*}\right)\right] \frac{\partial T}{\partial t}+q_{T},
$$

where $\lambda^{+}$is an abrupt change in the thermal conductivity at the interface between the solid phase and the liquid phase, $C_{T}$ denotes the convective component in the heat transfer equation

$$
C_{F}=v_{r} \frac{\partial F}{\partial r}+v_{z} \frac{\partial F}{\partial z}, F=\left[v_{r}, v_{z}, T\right] .
$$

Determination of the temperature of the liquid phase in the linear approximation. This problem is solved in the previous section, because in the linear approximation (excluding the convective components and the dissipative component in the right part of the equation (5) it coincides with the heat transfer equation in the tube):

$$
T^{(0)}(r, z, t)=\sum_{n, k}^{M, N} R_{m}(r) Z_{k}(z)\left[T 0_{m, k}+T 1_{m, k} e^{-\gamma_{m, k} t}\right] .
$$

The presence of a pressure gradient in the equations relative to the velocity of the melt is taken into account according to the equation $p=\rho R T$, i.e. $\partial p / \partial r=R \rho \partial T / \partial r, \partial p / \partial r=R \rho \partial T / \partial z$ taking into account (7).

Then the equation of motion can be written as follows:

$$
\begin{gathered}
\frac{\partial v_{r}}{\partial t}=-R \frac{\partial T^{(0)}}{\partial r}+\mu_{e}\left[\Delta v_{r}+\frac{\partial^{2} v_{z}}{\partial r \partial z}\right]-C_{v_{r}} \\
\frac{\partial v_{z}}{\partial t}=-R \frac{\partial T^{(0)}}{\partial z}+\mu_{e}\left[\Delta v_{z}+\frac{1}{r} \frac{\partial^{2} v_{r}}{\partial r \partial z}+\frac{1}{r} \frac{\partial}{\partial z}\left(\frac{\partial v_{r}}{\partial r}\right)\right]-C_{v_{z}} .
\end{gathered}
$$


Denote, as before, the linear part for the components of the velocity of the melt through $v_{r}^{(0)}(r, z, t), v_{z}^{(0)}(r, z, t)$ application of equations (8), (9) integral transformations on spatial variables gives for $m=1,2, \ldots$ :

$$
\begin{gathered}
\frac{d \overline{\overline{v_{r}^{(m)}}}}{d t}+\gamma_{n, k}^{v_{r}} \overline{\overline{v_{r}^{(m)}}}=-R \overline{\overline{T^{(m-1)}}}(t)=F_{r}^{(m-1)}(t)_{n, k}+\overline{\overline{C_{v_{r}}}} ; \\
\frac{d \overline{\overline{v_{z}^{(m)}}}}{d t}+\gamma_{n, k}^{v_{z}} \overline{\overline{v_{z}^{(m)}}}=-R \overline{\overline{T^{(m-1)}}}(t)=F_{z}(t)_{n, k}+\overline{\overline{C_{v_{z}}}} .
\end{gathered}
$$

Taking into account the expression (6) after the application of integral transformations of spatial variables in the "linear approximation" we will have

$$
\left(V^{(0)}\right)_{r}^{m, k}(p)=\frac{1}{p+\gamma_{m k}^{v_{r}}}\left[v r_{m, k}-\sum_{m_{1} k_{1}}^{M, K} r_{2 m m_{1}} z d_{k k_{1}}\left(\frac{T_{0 m_{1} k_{1}}}{p}+\frac{T_{1 m_{1} k_{1}}}{p+\gamma_{m_{1} k_{1}}^{T}}\right)\right],
$$

where $r_{2 m, m_{1}}, z d_{k, k_{1}}$ are the coefficients of integral transformations for the variables $r$ and $z$, respectively.

Summation in these expressions using the algorithm of equivalent simplification gives:

$$
\begin{aligned}
& \left(V^{(0)}\right)_{r}^{m, k}(p) \approx \frac{v r_{2}}{p}+\frac{v r_{0}+v r_{1} p}{v r_{3}+v r_{4} p+v r_{5} p^{2}} \\
& \left(V^{(0)}\right)_{z}^{m, k}(p) \approx \frac{v z_{2}}{p}+\frac{v z_{0}+v z_{1} p}{v z_{3}+v z_{4} p+v z_{5} p^{2}} .
\end{aligned}
$$

In these expressions indicated: $v r_{m, k}=r_{m} z_{k} v r_{0}, v z_{m, k}=r_{m} z_{k} v z_{0}$;

$$
r d_{m, m_{1}}=\int_{r_{a}}^{r_{b}} R_{m}\left(\beta_{m} r\right) \frac{\partial R_{m_{1}}}{\partial r}\left(\beta_{m_{1}} r\right) d r ; \quad z d_{k, k_{1}}=\int_{z_{0}}^{z_{l}} Z_{k}\left(\alpha_{k} z\right) \frac{\partial Z_{k_{1}}}{\partial z}\left(\alpha_{k_{1}} z\right) d z,
$$

where $v r_{0}, v z_{0}$ - initial values of velocity - the movement of the "traffic jam" in the longitudinal and radial directions.

The originals of these expressions are:

$$
\begin{gathered}
v r^{(0)}(r, z, t)==\sum_{m=1}^{M} R_{m}\left(\beta_{m} r\right) \sum_{k=1}^{N} Z_{k}(\alpha z) V r t_{m, k}^{(0)}(t) ; \\
V r t_{m, k}^{(0)}(t)=V r t_{0}+e^{-\gamma_{m, k}^{v_{r}} t}\left(V r t_{1} \sin \left(\omega_{v_{r}} t\right)+V r t_{2} \cos \left(\omega_{v_{r}} t\right)\right) ; \\
v z^{(0)}(r, z, t)=\sum_{m=1}^{M} R_{m}\left(\beta_{m} r\right) \sum_{k=1}^{N} Z_{k}(\alpha z) V z t_{m, k}^{(0)}(t) ; \\
V z t_{m, k}^{(0)}(t)=V z t_{0}+e^{-\gamma_{m, k}^{v_{z}} t}\left(V z t_{1} \sin \left(\omega_{v_{z}} t\right)+V z t_{2} \cos \left(\omega_{v_{z}} t\right)\right) .
\end{gathered}
$$

If there are expressions for the components of the melt velocity in the linear approximation, it is possible to determine the convective components in the equations for velocities and temperature. Substitute (7), (10), (11) to (6). Here is the expression for $C_{v_{r}}$. The expression for $C_{v_{z}}$ is similar. 


$$
\begin{aligned}
C_{v_{r}}^{(0)} & =\sum_{m_{1}, m_{2}}^{M} \sum_{k_{1}, k_{2}}^{K} R_{m_{1}}\left(\beta_{m_{1}} r\right) Z_{k_{1}}\left(\alpha_{k_{1}} z\right) V r t_{m_{1}, k_{1}}^{(0)}(t) \frac{d R_{m_{2}}\left(\beta_{m_{2}} r\right)}{d r} Z_{k_{2}}\left(\alpha_{k_{2}} z\right) V r t_{m_{2}, k_{2}}^{(0)}(t)+ \\
& +\sum_{m_{1}, m_{2}}^{M} \sum_{k_{1}, k_{2}}^{K} R_{m_{1}}\left(\beta_{m_{1}} r\right) Z_{k_{1}}\left(\alpha_{k_{1}} z\right) V z t_{m_{1} k_{1}}^{(0)}(t) R_{m_{2}}\left(\beta_{m_{2}} r\right) \frac{d Z_{k_{2}}\left(\alpha_{k_{2}} z\right)}{d z} V r t_{m_{2} k_{2}}^{(0)}(t) .
\end{aligned}
$$

Application of integral transformations by spatial variables to this expression leads to expressions of the form

$$
\begin{gathered}
\overline{\overline{C_{v_{r}}^{(0)}}}=\sum_{m_{1} m_{2}}^{M} \sum_{k_{1} k_{2}}^{K} F_{m_{1} m_{2} k_{1} k_{2}}^{m, k}(t) ; \\
F_{m_{1} m_{2} k_{1} k_{2}}^{m, k}(t)=F 1_{m_{1} m_{2} k_{1} k_{2}}^{m, k} V r t_{m_{1} k_{1}}^{(0)}(t) V r t_{m_{2} k_{2}}^{(0)}(t)+F 2_{m_{1} m_{2} k_{1} k_{2}}^{m, k} V z t_{m_{1} k_{1}}^{(0)}(t) V z t_{m_{2} k_{2}}^{(0)}(t) .
\end{gathered}
$$

Summation by indices $m_{1}, m_{2}, k_{1}, k_{2}$ using the algorithm of equivalent simplification [15], gives:

$$
C_{r}^{m, k}(p) \approx \frac{v r_{2}^{m, k}}{p}+\frac{v r_{0}^{m, k}+v r_{1}^{m, k} p}{v r_{3}^{m, k}+v r_{4}^{m, k} p+v r_{5}^{m, k} p^{2}}
$$

By a similar algorithm we obtain the expression for (12) whith (13):

$$
\begin{gathered}
C_{z}^{m, k}(p) \approx \frac{v z_{2}^{m, k}}{p}+\frac{v z_{0}^{m, k}+v z_{1}^{m, k} p}{v z_{3}^{m, k}+v z_{4}^{m, k} p+v z_{5}^{m, k} p^{2}} \\
C_{T}^{m, k}(p) \approx \frac{t_{2}^{m, k}}{p}+\frac{t_{0}^{m, k}+t_{1}^{m, k} p}{t_{3}^{m, k}+t_{4}^{m, k} p+t_{5}^{m, k} p^{2}} .
\end{gathered}
$$

The coefficients $v r_{j}^{m, k}, v z_{j}^{m, k}, t_{j}^{m, k}$ in convective components are determined using programs that implement the appropriate algorithms. Because the dissipative component in the equation for temperature can be written as

$$
q_{T}=\frac{2 A \mu_{e}}{\rho c 0_{V}}\left(\frac{\partial v_{r}}{\partial r}+\frac{\partial v_{z}}{\partial z}\right)^{2}
$$

taking into account (14)-(16) we will have

$$
Q_{T}^{m, k}(p) \approx \frac{2 A \mu_{e}}{\rho c 0_{V}}\left[\frac{T q_{2}}{p}+\frac{T q_{0}+T q_{1} p}{T q_{3}+T q_{4} p+T q_{5} p^{2}}\right] .
$$

Then in the first approximation for the temperature field in the image space we will have:

$$
{\overline{\overline{\overline{T^{(1)}}}}}_{m, k}(p)={\overline{\overline{\overline{T^{(0)}}}}}_{m, k}(p)-C_{T}^{m, k}(p)+{\overline{\overline{q_{T}}}}_{m, k}(p) \approx \frac{t 1_{m, k}^{0}+t 1_{m, k}^{1} p}{t 1_{m, k}^{3}+t 1_{m, k}^{4} p+t 1_{m, k}^{5} p^{2}} .
$$

Or in the space of the originals

$$
T^{(1)}(r, z, t)=\sum_{m=1}^{M} \sum_{k=1}^{N} R_{m}(r) Z_{k}(z) T T_{n, k}^{(1)}(t) ;
$$




$$
T T_{n, k}^{(1)}(t)=t 1_{m, k}^{(0)}-e^{-t 1_{m, k}^{(4)} t}\left(t 1_{m, k}^{(1)} f_{1}\left(t 1_{m, k}^{(5)} t\right)+t 1_{m, k}^{(2)} f_{2}\left(t 1_{m, k}^{(5)} t\right),\right.
$$

where $f_{1}(a t), f_{2}(a t)$ - originals from chains of the second order.

The calculation of these integrals according to the algorithms given in the section is performed once for all iterations. As a result of the solution for the components of the velocity of the melt and the temperature field acquire the following form:

$$
v_{r}^{(m)}(r, z, t)=\sum_{n=1}^{M} R_{n}(r) \sum_{k=1}^{N} Z_{k}(z) v r_{n, k}^{(m)}(t) ; \quad v_{z}^{(m)}(r, z, t)=\sum_{n=1}^{M} R_{n}(r) \sum_{k=1}^{N} Z_{k}(z) v z_{n, k}^{(m)}(t) .
$$

In Fig. 2 shows the graphs of the velocity components $v_{r}^{(m)}(r, z, t)$ :

Radial velocity $V_{r}(r, z, t=1)$ of melt $\mathrm{sm} / \mathrm{min}$

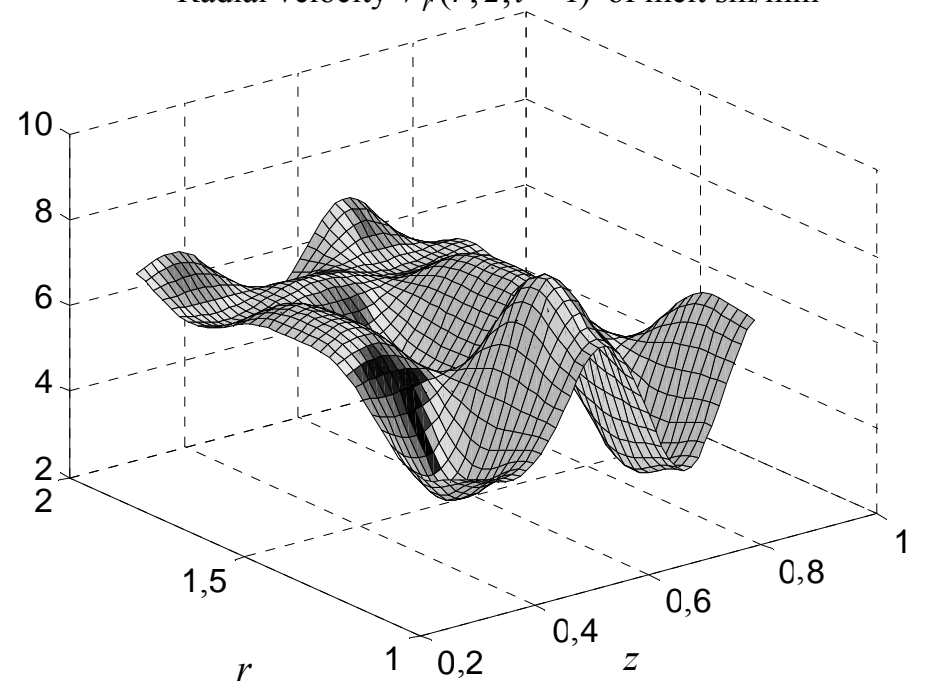

Fig. 2. Radial velocity field ( $\mathrm{sm} / \mathrm{min}$ )

In Fig. 3 shows the graphs of the velocity components $v_{z}^{(m)}(r, z, t)$ :

Axial velocity $V_{z}(r, z, t=1)$ of melt $-\mathrm{sm} / \mathrm{min}$

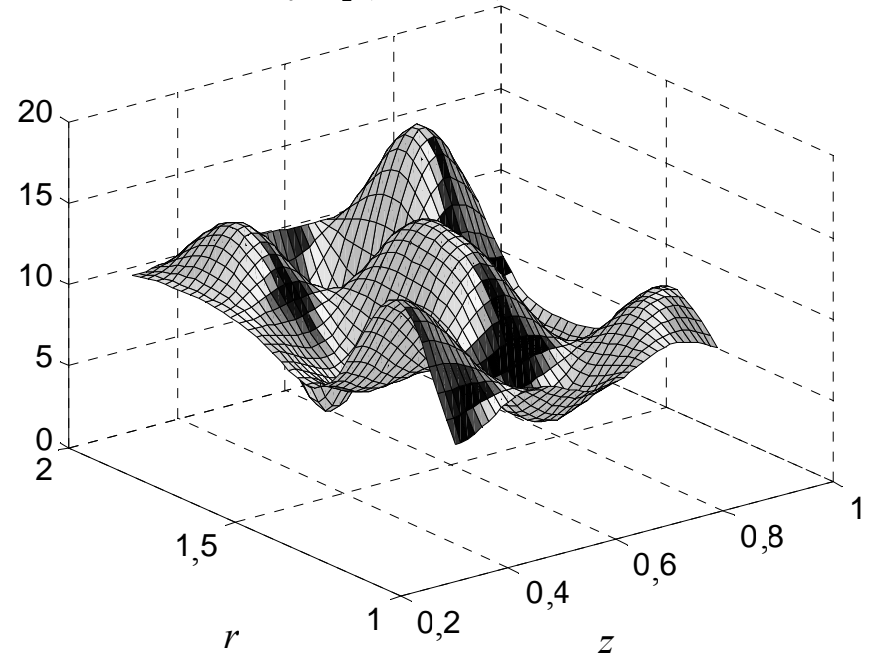

Fig. 3. Axial velocity field $(\mathrm{sm} / \mathrm{mi})$ 
The application of the iterative procedure for solving the nonlinear thermal equation can be written for the $m$-th approximation (Fig. 4):

$$
\begin{gathered}
T^{(m)}(r, z, t)=\sum_{m=1}^{M} \sum_{k=1}^{N} R_{m}(r) Z_{k}(z) T T_{n, k}^{(m)}(t) ; \\
T T_{n, k}^{(m)}(t)=t 1_{m, k}^{(0, m)}-e^{-t 1_{m, k}^{(4, m)} t}\left(t 1_{m, k}^{(1, m)} f_{1}\left(t 1_{m, k}^{(5, m)} t\right)+t 1_{m, k}^{(2, m)} f_{2}\left(t 1_{m, k}^{(5, m)} t\right) .\right.
\end{gathered}
$$

$T(r, z, t=2)$ of melt linear approximation

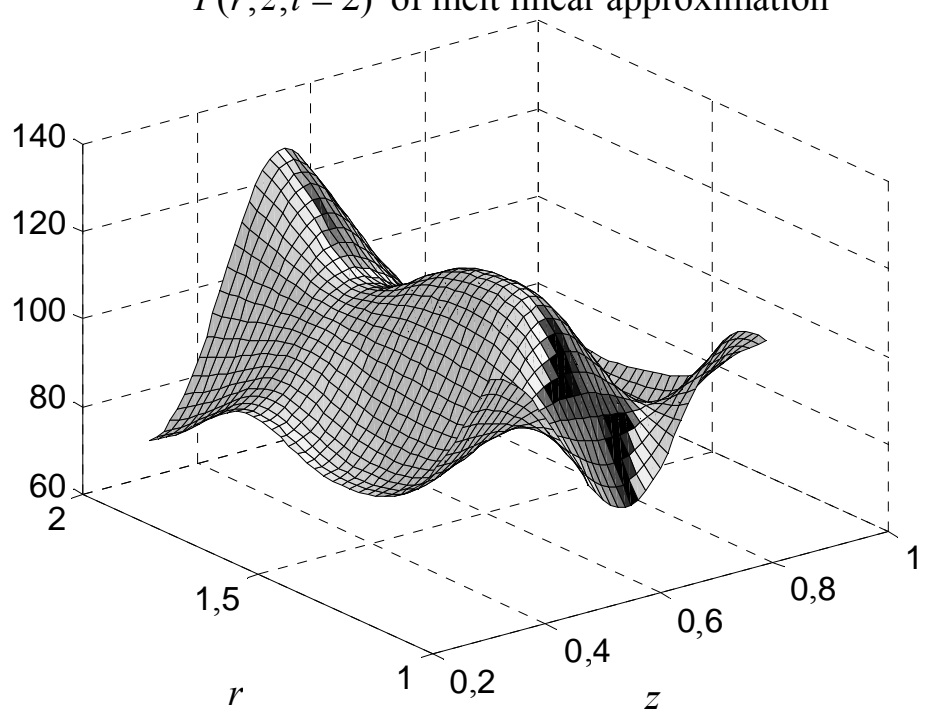

Fig. 4. Temperature field in linear approximation

Here are the graphs of the temperature fields obtained in the first 3 iterations (Fig. 5).

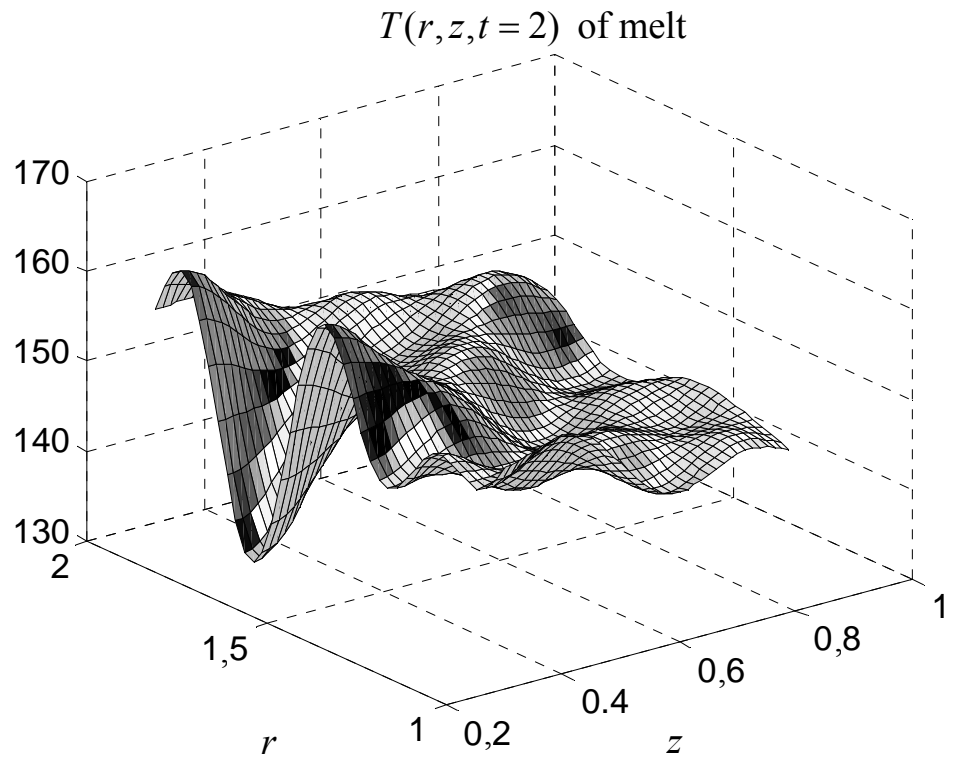

Fig. 5. Temperature field in the second approximation

According to the available approximate solution (17) whith (18) for the temperature field of the polymer melt in the first approximation we can write an expression for the pressure field 


$$
p^{(m)}(r, z, t)=\rho R T^{(m)}(r, z, t)=\sum_{n=1}^{M} \sum_{k=1}^{N} R_{n}(r) Z_{k}(z) T T_{n, k}^{(m)}(t)
$$

taking into account the expression (18) for $T T_{n, k}^{(m)}(t)$.

Since we are interested in the value of the pressure at the outlet of the melting zone of the polymer, it is appropriate to determine the value of the pressure at the boundary of the melting zone $L$ and the dosing zone:

$$
p^{(m)}(r, L, t)=\rho R T^{(m)}(r, L, t)=\sum_{n=1}^{M} \sum_{k=1}^{N} R_{n}(r) Z_{k}(L) T T_{n, k}^{(m)}(t) .
$$

The obtained solution of the problem of heating the "plug"- solid polymer mixture and the process of forming a thin film of melt at the end of the melting delay zone can be considered as the first step in determining the boundary of the phase transition solid phase - liquid phase.

The formation of the liquid phase is accompanied, of course, by a decrease in the proportion of solid phase. The melting process leads to the formation of a boundary $\left(r \in\left[r_{a}, r_{b}-\xi\right]\right)$ for the solid phase and $\left.r \in\left[r_{b}, r_{a}+\xi\right]\right)$ for the liquid phase.

A significant difference between the problem of phase transition in the process of polymer melting in contrast to the classical problems such as Stefan is that:

1 ) in the process of melting the polymer, the solid mixture moves in the direction of the axis $z$ with a speed of $V_{z}$;

2) this leads to the dependence of the variable boundary on the longitudinal coordinate $z$, ie $\xi=\xi(z)$.

\section{Defining the phase transition boundary}

At the boundary of the phase transition, the conditions of heat conservation at the free boundary separating the solid phase and the soluble one must be fulfilled:

$$
\left.L_{V} V_{n}\right|_{\Gamma}=\left.\frac{\lambda_{s}}{\rho_{s}} \frac{\partial T_{s}}{\partial n}\right|_{\Omega_{s}}-\left.\frac{\lambda_{l}}{\rho_{l}} \frac{\partial T_{l}}{\partial n}\right|_{\Omega_{l}},
$$

where $V_{n}=d \xi / d z$ is the velocity of the phase transition boundary, $L_{V}$ is the heat of the phase transition (determined experimentally).

The expression for the temperature field of the polymer mixture is obtained in the form:

$$
D_{n k}^{(0)}(t)=\sum_{n, k=1}^{M} e^{-\alpha_{n k} t}\left\{\begin{array}{cc}
e 1_{n k} \sin \omega_{n k} t+e 2_{n k} \cos \omega_{n k} t, & \omega_{n k}<0 ; \\
e 1_{n k} \operatorname{sh} \omega_{n k} t+e 2_{n k} \operatorname{ch} \omega_{n k} t, & \omega_{n k}>0 .
\end{array}\right.
$$

Then the solution in the first approximation will take the form

$$
T^{(1)}(r, z, t)=\sum_{n=1}^{M} \sum_{k=1}^{M} R\left(\delta_{n} r\right) Z\left(\beta_{k} z\right)\left[\frac{G_{n k}}{\eta_{n k}}\left(1-e^{-\eta_{n k} t}\right)+D_{n k}^{(0)}(t)\right] .
$$

Further approximations are implemented according to a similar scheme:

$$
T^{(m)}(r, z, t)=\sum_{n=1}^{M} \sum_{k=1}^{M} R\left(\delta_{n} r\right) Z\left(\beta_{k} z\right)\left[\frac{G_{n k}}{\eta_{n k}}\left(1-e^{-\eta_{n k} t}\right)+D_{n k}^{(m-1)}(t)\right] .
$$


For solid and liquid phases one can write:

$$
\begin{aligned}
& \frac{\partial T_{s}}{\partial n} \approx \frac{\partial T_{s}}{\partial r}=\left.\sum_{m=1}^{M} \frac{\partial B\left(\beta_{m} r\right)}{\partial r}\right|_{r=r_{b}^{\prime}} \sum_{k=1}^{K} Z\left(\alpha_{k} z\right) t t_{m, k}^{(s l)}(t) ; \\
& \frac{\partial T_{l}}{\partial n} \approx \frac{\partial T_{l}}{\partial r}=\left.\sum_{m=1}^{M} \frac{\partial B\left(\beta_{m} r\right)}{\partial r}\right|_{r=r_{a}^{\prime}} \sum_{k=1}^{K} Z\left(\alpha_{k} z\right) t t_{m, k}^{(p l)}(t) .
\end{aligned}
$$

Given that the density of the polymer material almost does not change with the transition from solid to liquid state, we have the following equation to determine the velocity of the phase interface:

$$
\begin{gathered}
V_{n}=\frac{d \xi}{d z}=\frac{1}{\rho L_{V}} \sum_{k=1}^{K} Z\left(\alpha_{k} z\right) C_{k} ; \\
\rho L_{V} V_{n}=\left.\frac{1}{\rho_{p l}} \sum_{m=1}^{M} \frac{\partial B\left(\beta_{m} r\right)}{\partial r}\right|_{r=r^{\prime}} \sum_{k=1}^{K} Z\left(\alpha_{k} z\right)\left[\lambda_{s} t t_{m, k}^{(s l)}(t)-\lambda_{l} t t_{m, k}^{(p l)}(t)\right] .
\end{gathered}
$$

Next, in order to obtain an expression for the phase separation boundary, we assume that the process of melting the polymer in the extruder with the formation of the phase transition boundary can be considered quasi-stationary. Then one can write the equation to determine the boundary of the phase transition as follows:

$$
C_{k}=\left.\frac{1}{\rho_{p l}} \sum_{m=1}^{M} \frac{\partial B\left(\beta_{m} r\right)}{\partial r}\right|_{r=r^{\prime}}\left[\lambda_{s} t t_{m, k}^{(s l)}(0)-\lambda_{l} t t_{m, k}^{(p l)}(0)\right] .
$$

The initial condition for this equation:

$$
\xi(0)=\frac{1}{\rho L_{V}} \sum_{k=1}^{K} Z\left(\alpha_{k} 0\right) C_{k} .
$$

As a result in Fig. 6 a graph of the velocity of the solid-liquid interface during melting of the polymer is given.

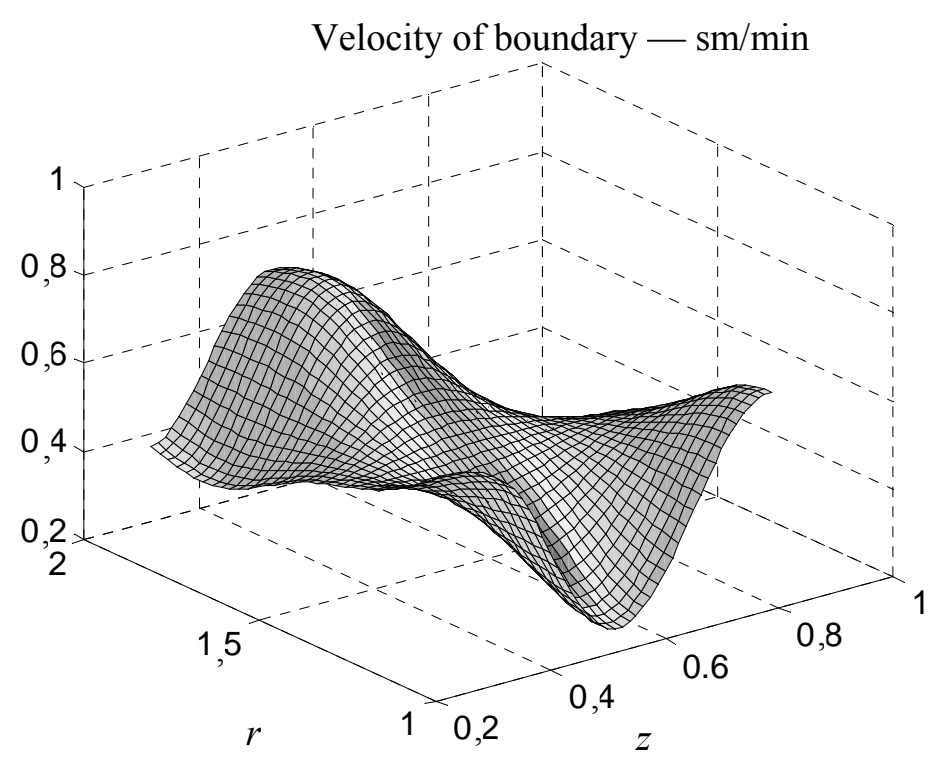

Fig. 6. Velocity of move of boundary solid-liquid $(\mathrm{sm} / \mathrm{min})$ 


\section{CONCLUSIONS}

1. The problem of modeling the processes of polymer melting in the extruder is formulated. The mathematical model of the process is a system of differential equations that takes into account the convective transfer of fluid, the nonlinear temperature dependence of the thermophysical parameters of the polymer and the dissipative component.

2. The solution of this system of equations is obtained using the iterative numerical-analytical method of solving nonlinear boundary value problems.

3 . The mathematical model of heat and mass transfer as a problem with variable limits is formulated - a problem like Stefan. A method for solving the problem of determining the moving boundary of phase separation solid phase liquid phase is proposed.

4. The obtained expression for the moving boundary can be used to set the problem of optimal control of the melting process of polymers.

\section{REFERENCES}

1. A. Gaspar, Modeling and optimization of single screw extrusion / dis ... doctor of science, 1999, $189 \mathrm{p}$.

2. G. Bizhanova and V. Solonnikov, "On problems with free boundaries for second-order parabolic equations", Algebra and analysis, vol. 12, issue 6, pp. 98-139, 2000.

3. M. Galanin, N. Prokushin, and A. Rodin, Solution of a three-dimensional nonstationary equation of thermal conductivity by the finite element method taking into account phase transitions. Moscow: KIAM preprints named after M.V. Keldysha, 2016, no. 66, 27 p.

4. R. Zainullin, "On an analytical approach to solving a one-dimensional problem of heat transfer with free boundaries", University news. Mathematics, no. 2. pp. 24-32, 2008.

5. V. Lyashenko and O. Kobylskaya, "Stefan type problem for a cylindrical domain", Physical and mathematical modeling and information technology, vol. 12, pp. 122-127, 2010.

6. V. Mitroshin and S. Kolpashchikov, "Automation of the process of applying polymer insulation in the manufacture of wired communication cables", Bulletin of Samara State University. Ser. Technical Sciences, no. 3 (59), pp. 28-40, 2018.

7. V. Mitroshin, Automation of technological processes of production of communication cables. Moscow: Mashinostroenie-1, 2006, $140 \mathrm{p}$.

8. E. Subbotin, A. Shcherbinin, and N. Trufanova, "Numerical study of polymer flow processes in the conditions of phase transition in the screw channels of extruders in the production of plastic insulation", Izvestiya Tomskogo polit. un-ta, vol. 320, no. 4, pp.171-177, 2002.

9. A. Shcherbinin, Processes of motion and heat exchange of nonlinear polymeric media in the conditions of phase transition in the channels of extrusion equipment. Author's abstract. dis .... Dr. tech. Science, 2006, 34 p.

10. C. Abeykoon, A. Kelly, and E. Brown, "The effect of materials, process settings, screw geometry on energy consumption and melt temperature in single screw extrusion", Applied Energy, vol. 180, pp. 880-894, 2016.

11. N. Altinkaynak, M. Gupta, and M. Spalding, "Melting in a Single Screw Extruder: Experiments and 3D Finite Element Simulations", Int. Polym. Proc., 26, pp. 182-196, 2011.

12. ANSYS Polyflow, CDF for Extrusion, Forming and Molding. ANSYS Inc.: Canonsburg, PA, USA, 2019.

13. R. Bur, S. Roth, and M. Spalding, "Temperature gradients in the channels of a singlescrew extruder”, Polymer Engineering \& Science, vol. 44, no. 11, pp. 2148-2157, 2004.

14. A. Samarsky and P. Vaibishevich, Computational heat transfer. Moscow, 2003, 785 p.

15. N. Zelenskaya and K. Zelensky, "Approximation of Bessel functions by rational functions", Electronics and control systems, no. 2 (44), pp. 123-129, 2015.

16. K. Zelensky, "Iterative method for solving nonlinear boundary value problems", Scientific Notes of Lutsk National University, vol. 26, no. 2, pp. 49-55, 2010. 
17. K. Zelensky, "Numerical-analytical method for solving space-time problems with moving boundaries", Int. scientific and technical Sat Adaptive automatic control systems, no. 14 (34), pp. 107-117, 2009.

Received 04.08.2021

\section{INFORMATION ON THE ARTICLE}

Olexander N. Trofymchuk, ORCID: 0000-0003-3358-6274, Institute of Telecommunications and Global Information Space of the National Academy of Sciences of Ukraine, Ukraine, e-mail: trofymchuk@nas.gov.ua

Kyryl Kh. Zelensky, ORCID: 0000-0003-1501-8214, Igor Sikorsky Kyiv Polytechnic Institute, Ukraine, e-mail: zelensky126@ukr.net

Vladimir A. Pavlov, ORCID: 0000-0002-6234-113X, Igor Sikorsky Kyiv Polytechnic Institute, Ukraine, e-mail: pavlov.vadimir264@gmail.com

Katerina S. Bovsunovska, ORCID: 0000-0003-0936-2246, Igor Sikorsky Kyiv Polytechnic Institute, Ukraine, e-mail: period0@ukr.net

МОДЕЛЮВАННЯ ПРОЦЕСІВ ТЕПЛОМАСОПЕРЕНЕСЕННЯ У ЗОНІ ПЛАВЛЕННЯ ПОЛІМЕРІВ / О.М. Трофимчук, К.Х. Зеленський, В.А. Павлов, К.С. Бовсуновська

Анотація. Досліджено питання тепломасотеплоперенесення полімерної суміші у циліндричних каналах. Особливість задачі, що розв'язується в роботі, полягає у наявності у каналі двофазних потоків тверда суміш — рідина під впливом нагрівання зовнішньої поверхні циліндра та дисипативних сил, які виникають унаслідок тертя суміші об стінки цього каналу. Розглянуто задачі нагрівання суміші, плавлення полімеру та визначення швидкості руху межі фазового переходу в умовах рухомої твердої суміші за рахунок обертального руху механізму, що подає суміш у циліндричний канал. Математичні моделі визначених процесів являють собою системи диференціальних рівнянь із частинними похідними математичної фізики; розв'язання відповідних крайових задач виконано із застосуванням числово-аналітичних методів, що дало змогу отримати розв'язки у квадратурах. Наведено результати комп'ютерного моделювання розроблених алгоритмів.

Ключові слова: еквівалентне спрощення, задача типу Стефана, інтегральні перетворення, полімерна суміш, рівняння Нав'є-Стокса, фазовий перехід, функції Бесселя.

МОДЕЛИРОВАНИЕ ПРОЦЕССОВ ТЕПЛОМАССОПЕРЕНОСА В ЗОНЕ ПЛАВЛЕНИЯ ПОЛИМЕРОВ / А.Н. Трофимчук, К.Х. Зеленский, В.А. Павлов, К.С. Бовсуновская

Аннотация. Исследованы вопросы тепломасопереноса полимерной смеси в цилиндрических каналах. Особенность задачи, решаемой в работе, заключается в наличии в канале двухфазных потоков твердая смесь - жидкость под воздействием нагревания наружной поверхности цилиндра и диссипативных сил, возникающих вследствие трения смеси в стенки этого канала. Рассмотрены задачи нагрева смеси, плавления полимера и определения скорости движения границы фазового перехода в условиях подвижной твердой смеси за счет вращательного движения подающего смесь в цилиндрический канал. Математические модели определенных процессов представляют собой системы дифференциальных уравнений с частными производными математической физики; решение соответствующих краевых задач выполнено с применением численно-аналитических методов, что позволило получить решения в квадратурах. Приведены результаты компьютерного моделирования разработанных алгоритмов.

Ключевые слова: задача типа Стефана, интегральные преобразования, полимерная смесь, уравнения Навье-Стокса, фазовый переход, функции Бесселя, эквивалентное упрощение. 